\begin{abstract}
Е.В. Градобоев
Иркутская государственная медицинская акаделия последиплолного образования - филиал Российской медииинской акаделии непрерывного профессионального образования Минздрава России,

г. Иркутск, Российккая Федерация
\end{abstract}

\begin{abstract}
АннотАция. Ситуация, когда в условиях несистематических рисков, обусловленных влиянием непрогнозируемых факторов, возникает необходимость реализации обоснованных способов регулирования состояния сферы здравоохранения, проявилась на практике в период угрозы состоянию здоровья населения. В связи с этим теоретическое обоснование способов реализации функций управления здравоохранением на основании оценки состояния и этапности развития является актуальным направлением исследования. На основе исследования угроз экономической безопасности социально-экономической системы со стороны здравоохранения в регионах Российской Федерации в статье рассматриваются основные положения теории жизненных циклов и проводится оценка правомерности сформулированной гипотезы о ее применимости к модели финансирования здравоохранения. В статье с учетом обоснования правомерности авторской гипотезы о зависимости экономической безопасности социально-экономической системы от механизма финансирования здравоохранения выдвигаются требования к методологическому подходу, применяемому к модели оценки экономической безопасности региона. Показано, что на базе реализации основных положений теории жизненного цикла при условии их содержательного развития возможно формирование такой модели эволюционного преобразования механизма финансирования здравоохранения, которая обеспечит устойчивое состояние социально-экономической системы региона. Сформулированы требования к модели финансирования здравоохранения, обеспечивающей необходимое состояние экономической безопасности региональной социально-экономической системы.
\end{abstract}

кЛЮчЕВЫЕ слоВА. Социально-экономическая система, жизненный цикл, устойчивость, проблемы развития региона, финансирование здравоохранения, инструменты урегулирования конфликтов.

ИНФОРМАЦИЯ О СТАТЬЕ. Дата поступления 8 февраля 2021 г.; дата принятия к печати 21 июня 2021 г.; дата онлайн-размещения 13 июля 2021 г.

E.V. Gradoboev

Irkutsk State Medical Academy of Postgraduate Education, Branch of Ministry of Healthcare of the Russian Federation State Budgetary Educational Institution for Continuing Professional Education, Irkutsk, Russian Federation

\title{
METHODOLOGICAL FEATURES OF THE FORMATION OF THE MODEL OF HEALTHCARE FINANCING
}

\begin{abstract}
The situation when, in the context of unsystematic risks caused by the influence of unpredictable factors, there is a need to implement reasonable methods of regulating the state of the health sector, manifested itself in practice during the period of threat to public health. In this regard, the theoretical substantiation of the ways of implementing the functions of healthcare management based on the assessment of the state and stages of development is an urgent area of research. Based on the study of threats to the economic security of the socio-economic system from healthcare in the regions of the Russian Federation, the article examines the main provisions of the theory of life cycles and evaluates the legitimacy of the formulated hypothesis about its applicability to the healthcare financing model. In the article, taking into
\end{abstract}

(C) Градобоев E.B., 2021

\section{Baikal Research Journal}

электронный научный журнал Байкальского государственного университета 
account the substantiation of the legitimacy of the author's hypothesis about the dependence of the economic security of the socio-economic system on the healthcare financing mechanism, the requirements for the methodological approach to the model for assessing the economic security of the region are proposed. It is shown that on the basis of the implementation of the main provisions of the life cycle theory, subject to their meaningful development, it is possible to form such a model of the evolutionary transformation of the healthcare financing mechanism, which ensures a stable state of the socio-economic system of the region. Requirements for the healthcare financing model, which ensure the necessary state of economic security of the regional socio-economic system, are formulated.

KEYWORDS. Socio-economic system, life cycle, sustainability, development problems, healthcare financing, conflict resolution tools.

ARTICLE INFO. Received February 8, 2021; accepted June 21, 2021; available online July 13, 2021.

\section{Введение}

Актуальность ситуации с устойчивостью социально-экономической системы приобретает особую значимость в условиях реализации несистематических рисков экономической безопасности. Проявление этой категории рисков идентифицируется на основании индивидуальных признаков, поскольку универсальных критериев оценки их наличия и уровня проявления не существует [1].

Источником несистематических рисков в системе национальной экономической безопасности является состояние сферы здравоохранения, причем различные авторы выделяют три основных направления угроз состоянию системы здравоохранения.

1. Собственно состояние здравоохранения на региональном уровне. Проблемы социально-экономического развития региона и конкретно вопросы оценки влияния системы здравоохранения на уровень социально-экономического развития достаточно широко освещены в трудах отечественных ученых [2-8]. Так, с точки зрения авторов монографии «Организационно-экономические факторы управления региональной системой здравоохранения», «здравоохранение является подсистемой региональной экономики», так как удовлетворяет следующим классификационным признакам:

- структурный (подсистема здравоохранения входит в состав системы региона как ее сложный структурный компонент);

- функциональный (функция подсистемы здравоохранения заключается в ориентации на достижение общих целей системы - вклад в региональный доход и в трудовой потенциал региона, обеспечение жизнедеятельности жителей региона);

- коммуникационный (подсистема связана с другими компонентами и подсистемами системы региона финансовыми, административными, информационными и другими связями, она гармонически вписывается в общий структурно-функциональный контекст системы и действует не только по сугубо «внутренним», специфическим законам, но и по законам, определяющим функционирование системы в целом) [8, с. 9].

2. Модели и методы оценки эффективности как часть экономического механизма регулирования состояния региональной сферы здравоохранения. Такой точки зрения придерживается и Е.В. Лобкова, она считает, что «оптимизацию регионального здравоохранения следует проводить исходя из параметров медико-социальной эффективности системы» [9, с. 698].

На основании такой точки зрения С.И. Трибунским был предложен методологический подход к анализу общественного здоровья, «основанный на оценке и обобщающей характеристике социально-гигиенических и экономических факто-

\section{Baikal Research Journal}

электронный научный журнал Байкальского государственного университета 
ров, в том числе в изучении их влияния на здоровье населения, который позволил исследовать связь между динамикой параметров социально-экономического развития субъектов Сибирского федерального округа и характеристиками здоровья населения» [10].

Более того, используемые инструменты управления, как показала в своем исследовании Т.А. Прокофьева, не в полной мере соответствуют критериям эффективного развития региона, а именно - «применяемая в регионах модель программно-целевого управления развитием здравоохранения не в полной мере реализует потенциал такого управления». Это проявляется в двух аспектах:

- разработка программных мероприятий не всегда основывается на определении стратегических целей и направлений развития здравоохранения;

- процесс бюджетирования зачастую не увязан с конкретными программными выходами, т.е. отсутствует конкретный результат, отражаемый системой количественных и качественных индикаторов [11, с. 8].

3. Объемы и механизмы финансирования здравоохранения. Ситуация в отдельных регионах, в том числе входящих в состав Сибирского федерального округа, подтверждает факт определяющего влияния инструментов финансирования на состояние социально-экономических показателей региона [12].

В настоящее время обязательное медицинское страхования (далее - ОМС) является одним из основных стабильно совершенствующихся социальных институтов, гарантирующих гражданам полное и своевременное получение медицинской помощи $[13 ; 14]$. Эта гарантия воплощается посредством фонда, сформированного из страховых взносов на OMC и в объемах, гарантированных законодательством России. За последнее десятилетие, как свидетельствуют статистические данные, объем доходов и расходов бюджета Федерального фонда ОМС (ФФОМС) вырос более чем в 20 раз: со 109 млрд р. в 2010 г. до почти 2,2 трлн р. в 2019 г. Следовательно, в такой же пропорции увеличился и объем средств, направленных в Территориальные фонды ОМС (ТФОМС) в виде субвенций для дальнейшей оплаты медицинской помощи в субъектах Федерации [15].

Поскольку способ финансирования является неотъемлемой составляющей экономического механизма, а состояние государственной социально-экономической системы здравоохранения определяется соответственно на основании состояния региональных подсистем, представляется возможным предположение о том, что предметом исследования закономерностей регулирования сферы здравоохранения (как специфического элемента социально-экономической системы) в большинстве случаев является способ финансирования здравоохранения.

Полагаем, что методология исследования здравоохранения как специфического элемента социально-экономической системы региона должна строиться в рамках подтвержденной достоверности гипотезы о том, что существует устойчивая зависимость между механизмом финансирования системы здравоохранения и состоянием экономической безопасности социально-экономической региональной системы.

Сформулированная научная гипотеза справедлива с теоретической точки зрения, поскольку система здравоохранения как подсистема региональной социально-экономической системы обеспечивает, с одной стороны, достижение целей регионального развития (сохранение и преумножение основной государственной ценности - человеческого капитала), а с другой - основную ресурсную составляющую (трудовые ресурсы).

\section{Модели и методы}

В связи с теоретической гипотезой, рассматриваемой в рамках изменения уровня устойчивости социально-экономической системы под влиянием несистемати-

\section{Baikal Research Journal}

электронный научный журнал Байкальского государственного университета 
ческих рисков, обусловленных способом финансирования региональной системы здравоохранения, представляется важным определение наиболее общей модели описания изменений подсистемы здравоохранения как источника угроз состояния системы в целом. Для оценки достоверности сформулированной теоретической гипотезы модель описания объекта должна отражать связь между количественной оценкой состояния объекта и возможностью регулирования состояния в рамках внешних по отношению к объекту механизмов.

Ведущие специалисты в системе организации и финансового обеспечения здравоохранения отмечают относительно положительный результат введения системы ОМС как необходимой меры по поддержанию функционирования медицинских учреждений в кризисный период, однако нельзя не подчеркнуть, что ее уязвимость, по причине жесткой зависимости от источников финансирования, сохранилась [16]. Если с начала 1990-х гг. государство утратило возможность самостоятельно нести бремя финансового обеспечения медицинских услуг, то в последние годы, в связи со снижением платежеспособности и уровня благосостояния основной массы населения, тандем государства и населения перестал справляться с ролью гаранта поддержания функциональной устойчивости системы здравоохранения. Таким образом, многие авторы отмечают в качестве основной проблемы развития системы OMC недостаточное или неэффективное финансирование здравоохранения [17].

В 2019 г. были установлены новые правила ОМС, которые позволили объединить все усилия по сотрудничеству подразделений для увеличения контроля над процессом прохождения медицинского лечения граждан. Представленная в публикациях Н.В. Журавлевой, Д.С. Лопаткина оценка системы ОМС как гарантии надежности системы финансирования здравоохранения [18] подразумевает тот факт, что проблемы организации и недостаточной эффективности первой переносятся в полной мере на российскую систему финансирования здравоохранения, построенную в целом в соответствии с законодательством ${ }^{1}$.

Авторский анализ перечня и видов источников формирования доходной части бюджета ФФОМС, степень его финансового участия в деятельности ТФОМС, особенности финансирования медицинской помощи, а также роль бюджета в выполнении функций последнего послужили выбору основополагающих классификационных признаков для выделения этапов эволюционного развития экономических отношений. Перечисленные критерии позволяют определить три основные этапа эволюционного развития бюджетных и экономических отношений в сфере OMC:

- зарождение и становление (1993-2004 гг.);

- взросление и интенсивный рост (2005-2011 гг.);

- централизация и качественное развитие (2012 г. - по настоящее время) [19].

Дальнейшее развитие сформулированных положений было продолжено на основании исследования этапности экономических отношений.

Одним из методологических подходов к оценке правомерности сформулированной гипотезы можно считать теорию жизненного цикла, а также работы, посвященные изучению организационной эффективности объектов, функционирующих в соответствии с различными признаками, определяющими этап жизненного цикла их развития. В первую очередь здесь нужно отметить работу А. Доунса (А. Downs, 1967) [20; 21].

В процессе проведенного авторского исследования были выделены базовые характеристики цикличности, сформулированные в различных подходах к модели жизненного цикла.

1 Об обязательном медицинском страховании в Российской Федерации : федер. закон от 29 нояб. 2010 г. № 326-ФЗ : (в ред. от 6 февр. 2019 г.) // СПС «КонсультантПлюс».

\section{Baikal Research Journal}

электронный научный журнал Байкальского государственного университета 
1. Количество этапов (стадий) жизненного цикла и возможность их увязки с инструментами управления состоянием объекта управления.

Существует многообразие точек зрения на количество этапов (стадий) жизненного цикла: А. Доунс и Д. Катц (D. Katz, R.L. Kahn, 1978) предлагали модели из трех стадий [22]; Ф. Лайден (F. Lyden, 1975) считает, что стадий должно быть четыре [23]; модель Л. Грейнера (L. Greiner, 1972) содержит пять стадий [24]; модель В. Торберта (W. Torbert, 1975) - девять стадий [25]; модель И. Адизеса десять [26]. При этом авторы делают акцент на различные наборы уникальных характеристик каждой стадии соответствующей модели жизненного цикла.

К примеру, модель А. Доунса включает три основные стадии роста и развития - «борьба за выживание», «стремительный рост», «замедление». Он связывает с ними различные функции управления: установление, обоснованность, инновационное развитие и расширение, а затем формализация и контроль [22].

В своей модели Г. Липпит и У. Шмидт (G.L. Lippitt, W.H. Schmidt, 1967) представляют три стадии развития организации - рождение, молодость, зрелость, и шесть основных задач управления, которые переходят из одной стадии управления в другую [27].

Пять стадий выделяют Дж. Кимберли и P. Майлз (J.R. Kimberly, R.H. Miles, 1980). По их мнению, первая стадия развития организации наступает до ее фактического создания, и связана она с формированием будущей идеологии. На второй стадии происходит становление организации, на третьей формируется ее идентичность, на четвертой - идет процесс ужесточения управления и организационной структуры, сама организация становится консервативной и предсказуемой [28].

В модели Дж. Агарони, Х. Фалька и Н. Иехуды (J. Aharony, H. Falk, N. Yehuda) четыре стадии развития. Они различаются такими характеристиками, как степень неопределенности и вероятности, структура активов, наличие возможностей для осуществления инвестиций [29].

Концепция Ю.Д. Мироненко и А.К. Тереханова предполагает линейную модель с пятью уровнями организационного развития: реализованная бизнес-идея, структуризация, рациональное управление процессами, рациональное управление потенциалом компании, рациональное управление нематериальными активами предприятия [30]. Особенность модели с точки зрения управления заключается в том, что она рассматривает развитие системы менеджмента, а не организации в целом, т.е. позволяет формализовать процесс управления на различных этапах жизненного цикла на основании преимущественного инструмента управления.

2. Связь между этапами и проблемами развития объекта, обусловленными внешним окружением.

B теории Ф. Лидена (F. Lyden, 1975) организация на различных стадиях своего развития имеет проблемы, препятствующие нормальному функционированию: проблема адаптации к окружающей среде, захват определенного сегмента рынка, приобретение ресурсов, достижение поставленных целей, поддержка образцов поведения [23].

Теория Д. Каца и P. Кана (D. Katz, R.L. Kahn, 1978) представляет организационную структуру как отражение изменений, происходящих в организации в зависимости от стадии ее развития [22]. В организации три стадии развития (простые системы, устойчивая стадия, разработка структуры). Организация представлена как открытая система, успех (или преодоление фатальных проблем) которой зависит от ее активного взаимодействия с окружающей средой.

В рамках своей теории Д. Лестер, Дж. Парнелла, А. Карраген (D.L. Lester, J.A. Parnell, A. Carraher, 2003) разработали эмпирическую шкалу количественного измерения стадий жизненного цикла организаций для предсказания измене-

\section{Baikal Research Journal}

электронный научный журнал Байкальского государственного университета 
ний характеристик организаций при переходе с одной стадии жизненного цикла на другую [31].

Жॅизненный цикл организации в модели Липпита - Шмидта (G.L. Lippitt and W.H. Schmidt, 1967) связывается с идентификацией на каждой стадии развития проблемы и последствий для состояния объекта сохранения проблемной ситуации [27]. Кроме того, сформулированы факторы риска, которые приводят к проблемной ситуации. Концепция Липпитта и Шмидта основывается на идее, что в жизненном цикле организация проходит через последовательность стадий роста, и каждый очередной кризис или ситуация требует специфического управления или реакции, необходимых для перехода к следующей стадии. Основным критерием для определения стадии развития являются действия, которые применяются для разрешения предсказуемых организационных кризисов. Впоследствии Липпит назвал это моделью ситуационной конфронтации, и это предлагает, с точки зрения дальнейшего развития модели, ответственность управляющей подсистемы за разрешение кризисов таким образом, чтобы создать прочную основу для преодоления будущих кризисов [32].

3. Способы (инструменты) обеспечения устойчивого состояния.

На каждом из этапов жизненного цикла устойчивость состояния в условиях нестабильного внешнего окружения решается на разных стадиях развития разными методами.

3.1. На стадии становления и раннего развития первостепенной заботой организации является поиск источников денежных ресурсов для обеспечения ее выживания [27; 28]. Методы, с помощью которых организация достигает долгосрочной стабильности - это неформальные коммуникации [24] и неформальная организационная структура [33].

3.2. Стадия развития характеризуется необходимостью обеспечения стабильного и сбалансированного роста, причем во всех направлениях деятельности и с привлечением всех возможных, в том числе и административных ресурсов [28]. Особенность решения главной проблемы этапа - обеспечение роста в условиях необходимости обеспечения баланса интересов организации и внешнего окружения - должна отвечать условиям изменения отношений как внутри элементов самой организации, так и с внешней средой, в том числе за счет достижения более высокого уровня обязательств организации [34]. Причем особая роль инвестиций как ресурса обеспечивается, по мнению В. Торберта, следующими условиями:

- организаторы принимают на себя определенные обязательства;

- «родительские» учреждения берут на себя финансовые, структурные и духовные обязательства по воспитанию;

- осуществляется раннее построение отношений между потенциальными лидерами, членами, клиентами и советниками;

- реализуется согласованный стиль руководства;

- возникают вопросы относительно достоверности, надежности и глубины различных личных и институциональных обязательств [25].

В своей более ранней работе В. Торберт отмечает важность связи между стадией жизненного цикла и характером конфликтных ситуаций, разрешение которых и определяет основные задачи управления, реализуемые на конкретной стадии [33].

В процессе работы и достижения определенного уровня развития и результатов деятельности (на стадии «зрелость») могут возникнуть такие проблемы, которые потребуют пересмотра всей концепции управления и бизнеса, например:

- изменение государственной политики регулирования предпринимательской деятельности, в том числе налоговой политики;

\section{Baikal Research Journal}

электронный научный журнал Байкальского государственного университета 
- удорожание источников информации, разрушение личных деловых связей и договоренностей;

- недостаток достоверной и достаточной информации о правах и полномочиях контролирующих органов;

- бессистемный характер проверок со стороны контрольно-ревизионных структур.

\section{Выводы и результаты}

Базовые положения модели жизненного цикла являются приемлемым методологическим подходом для подтверждения достоверности авторской теоретической гипотезы о существовании устойчивой зависимости между механизмом финансирования здравоохранения и состоянием экономической безопасности социально-экономической региональной системы в силу следующих положений:

1. Анализ эмпирических данных позволяет выделить этапы развития способов финансирования здравоохранения и однозначно идентифицировать инструменты управления оказанием медицинской помощи населению на каждом этапе.

2. Идентификация этапов (стадий) возможна на основании значений количественно исчислимых показателей, идентифицирующих угрозы состоянию экономической безопасности социально-экономической региональной системы, обусловленные внешним окружением и противоречиями между элементами самой подсистемы здравоохранения.

3. Существуют и практически апробированы способы (инструменты) обеспечения устойчивого состояния экономической безопасности региональной социально-экономической системы, причем выбор и применение методов финансирования здравоохранения обусловлены институциональными требованиями внешнего окружения.

Обоснованное использование теории жизненных циклов к реализации теоретических положений авторской научной гипотезы позволяет сформулировать следующие требования к модели финансирования здравоохранения, обеспечивающей необходимое состояние экономической безопасности региональной социально-экономической системы:

- наличие стратегической (долгосрочной) цели социально-экономической системы региона, сформулированной в терминах стабильности (устойчивости) состояния защищенности;

- возможность идентификации угроз экономической безопасности, возникающих под воздействием изменения состояния подсистемы здравоохранения региональной социально-экономической системы;

- идентификация конфликтных ситуаций, обусловленных механизмом финансирования, между элементами подсистемы здравоохранения региональной социально-экономической системы;

- измеримость и однозначная оценка целевых показателей социально-экономической системы региона, характеризующих уровень (степень) разрешения конфликтных ситуаций, связанных с механизмом финансирования здравоохранения.

\section{Список использованной литературы}

1. Лобкова Е.В. Управление эффективностью региональной системы здравоохранения / Е.В. Лобкова, А.С. Петриченко // Финансы и кредит. - 2020. - Т. 26, № 3 (795). C. $698-720$.

2. Положенцева Ю.С. Анализ эффективности системы здравоохранения: основные тенденции развития и перспективы модернизации / Ю.С. Положенцева, Н.С. Муштенко, А.Д. Хомутинникова // Известия Юго-Западного государственного университета. Серия: Экономика. Социология. Менеджмент. - 2020. - Т. 10, № 3. - С. 123-139.

\section{Baikal Research Journal}


3. Ерженин Р.В. Оценка влияния качества управления в региональной системе здравоохранения на качество жизни населения / Р.В. Ерженин // Здоровье и качество жизни : материалы III Всерос. конф. с междунар. участием. - Иркутск, 2018. - С. 87-94.

4. Рубцова В.Н. Стратегический подход к формированию механизма государственной здравоохранительной политики / В.Н. Рубцова // Вестник Саратовского государственного социально-экономического университета. - 2019. — № 3 (77). — С. 143-147.

5. Кудрина В.Г. Теория и практика индикативного планирования в здравоохранении / В.Г. Кудрина, Д.О. Сапралиева // Здравоохранение Российской Федерации. — 2016. Т. 60, № 2 . - С. 60-65.

6. Прохода В.А. Оценка национальной системы здравоохранения жителями России и других европейских стран / В.А. Прохода // Политика и общество. — 2018. — № 10 . C. $65-77$.

7. Карташова Н.А. Проведение независимой оценки качества медицинских услуг в учреждениях здравоохранения как условие повышения качества жизни населения Магаданской области (на примере ОГБУЗ «Магаданская областная детская больница») / Н.А. Карташова // Вестник Северо-Восточного государственного университета. — 2020. — № 33. - С. 59-67.

8. Калашников К.Н. Организационно-экономические факторы управления региональной системой здравоохранения : монография / К.Н. Калашников, А.А. Шабунова, М.Д. Дуганов. - Вологда : ИСЭРТ РАН, 2012. - 153 с.

9. Лобкова Е.В. Управление эффективностью региональной системы здравоохранения / Е.В. Лобкова // Финансы и кредит. - 2020. - № 3. - С. 4-9.

10. Трибунский С.И. Социально-экономическая обусловленность здоровья сельского населения и научное обоснование модели здравоохранения : автореф. дис. ... д-ра мед. наук : 14.02.03 / С.И. Трибунский. - Новокузнецк, 2012. - 46 с.

11. Прокофева Т.А. Государственное управление развитием здравоохранения региона и его совершенствование : автореф. дис. ... канд. экон. наук : 08.00.05 / Т.А. Прокофева. Воронеж, 2007. - 22 с.

12. Канева М.А. Основные направления развития системы здравоохранения на федеральном и региональном уровнях (на примере Новосибирской области) / М.А. Канева // Актуальные проблемы развития Новосибирской области и пути их решения : сб. науч. тр. - Новосибирск, 2014. - С. 269-297.

13. Голикова Т. Что ждет российское здравоохранение в 2009 году? Качество услуг организаций, работающих в системе ОМС, будет оцениваться по новым критериям / Т. Голикова // Менеджер здравоохранения. - 2008. - № 12. - С. 4-6.

14. Тягний И.С. Обязательное медицинское страхование / И.С. Тягний, С.А. Зяблицева // Modern Science. — 2019. - № 12-1. - С. 429-432.

15. Шелякин В.А. Конструкция финансового регулирования в системе обязательного медицинского страхования / В.А. Шелякин // Урал - драйвер неоиндустриального и инновационного развития России : материалы I Урал. экон. форума. - Екатеринбург, 2019. - C. $235-238$.

16. Территориальная программа государственных гарантий бесплатного оказания гражданам медицинской помощи в Саратовской области на 2019 год и на плановый период 2020 и 2021 годов // Актуальные вопросы общественного здоровья и здравоохранения на уровне субъекта Российской Федерации : материалы всерос. науч.-практ. конф., посвящ. 100-летию Иркутского гос. мед. ун-та (1919-2019) / под ред. Г.М. Гайдарова. - Иркутск, 2019. - С. 253-259.

17. Решетников А.В. Участие структур обязательного медицинского страхования в реализации национального проекта «Здравоохранение» / А.В. Решетников // Региональное здравоохранение: современное состояние и основные направления реализации национального проекта «Здравоохранение» : сб. тр. конф. - Ростов-на-Дону, 2019. - С. 12-19.

18. Журавлева Н.В. Обязательное медицинское страхование как источник финансирования здравоохранения / Н.В. ЖЖравлева, Д.С. Лопаткин // Финансы и кредит. 2013. - № 10. - С. 63-66.

19. Устюгов А.В. Эволюционное развитие финансовых механизмов в сфере обязательного медицинского страхования / А.В. Устюгов, Е.В. Градобоев // Обязательное медицинское страхование в Российской Федерации. - 2018. - № 5. - С. 42-49.

\section{Baikal Research Journal}

электронный научный журнал Байкальского государственного университета 
20. Downs A. The Life Cycle of Bureaus / A. Downs // Inside Bureaucracy. - Boston : Little, Brown and Company, 1967. - P. 296-309.

21. Smith K.G. Top Level Management Priorities in Different Stages of the Organizational Life Cycle / K.G. Smith, T.R. Mitchell, C.E. Summer // Academy of Management Journal. 1985. - Vol. 28, no. 4. - P. 799-820.

22. Katz D. The Social Psychology of Organizations / D. Katz, R.L. Kahn. - New York : Wiley, 1978. - $485 \mathrm{p}$.

23. Lyden F. Using Parsons' functional analysis in the study of public organizations / F. Lyden // Administrative Science Quarterly. - 1975. Vol. 20, no. 1. - P. 59-70.

24. Greiner L. Evolution and Revolution as Organization Grow / L. Greiner // Harvard Business Review. - 1972. - Vol. 50, no. 4. - P. 37-46.

25. Адизес И. Управление жизненным циклом корпорации / И. Адизес. - Санкт-Петербург : Питер, 2011. - 383 с.

26. Torbert W. Pre-bureaucratic and Post-bureaucratic Stages of Organization Development / W. Torbert // Interpersonal Development. - 1974. - Vol. 5, no. 1. - P. 1-25.

27. Lippitt G.L. Crises in a Developing Organization / G.L. Lippitt, W.H. Schmidt // Harvard Business Review. - 1967. - Vol. 45, no. 6. - P. 102-112.

28. Kimberly J.R. The Organizational Life Cycle / J.R. Kimberly, R.H. Miles. — San Francisco : Jossey Bass, 1980. - 492 p.

29. Aharony J. Corporate Life Cycle and the Relative Value - Relevance of Cash Flow versus Accrual Financial Information / J. Aharony, H. Falk, N. Yehuda // Working Paper. 2006. — URL: https://www.researchgate. net/publication/228170690.

30. Мироненко Ю.Д. Роль стратегии изменений организации в ее развитии / Ю.Д. Мироненко, А.К. Тереханов // Менеджмент. - 2004. - № 5. — URL: http://www.management. com.ua.

31. Lester D.L. Organizational Life Cycle: A Fivestage Empirical Scale / D.L. Lester, J.A. Parnell, A. Carraher // The International Journal of Organizational Analysis. — 2003. Vol. 11, no. 4. - P. 339-354.

32. Mosca L. Organizational Life Cycle Models: a Design Perspective / L. Mosca, M. Gianecchini, D. Campagnolo // Journal of Organization Design. - 2021. - URL: https://doi. org/10.1186/s41469-021-00090-7.

33. Torbert W. Creating a Community of Inquiry. Conflict, Collaboration, Transformation / W.Torbert. - London : Wiley, 1976. - $184 \mathrm{p}$.

34. Мильнер Б.3. Теория организации : учебник / Б.З. Мильнер. - Москва : ИНФРА-M, 2009. - 654 c.

\section{Информация об авторе}

Градобоев Евгений Валерьевич - кандидат экономических наук, доцент, кафедра общественного здоровья и здравоохранения, Иркутская государственная медицинская академия последипломного образования - филиал Российской медицинской академии непрерывного профессионального образования Минздрава России, г. Иркутск, Российская Федерация, e-mail: gradoboev_eugene@mail.ru.

\section{Author}

Evgeny V. Gradoboev - PhD in Economics, Associate Professor, Department of Public Health and Healthcare, Irkutsk State Medical Academy of Postgraduate Education, Branch of Ministry of Healthcare of the Russian Federation State Budgetary Educational Institution for Continuing Professional Education, Irkutsk, Russian Federation, e-mail: gradoboev_eugene@mail.ru.

\section{Для цитирования}

Градобоев Е.В. Методологические особенности формирования модели финансирования здравоохранения / E.B. Градобоев. - DOI 10.17150/2411-6262.2021.12(2).6 // Baikal Research Journal. - 2021. — T. 12, № 2.

\section{For Citation}

Gradoboev E.V. Methodological Features of the Formation of the Model of Healthcare Financing. Baikal Research Journal, 2021, vol. 12, no. 2. DOI: 10.17150/2411-6262.2021.12(2).6. (In Russian).

\section{Baikal Research Journal}

